\title{
Physico-chemical and biotic factors influencing microalgal seed culture propagation for inoculation of a large scale raceway pond
}

\author{
Mutanda, T. ${ }^{1 *}$, Ranjith Kumar R. ${ }^{2}$ and Bux, $F^{2}$ \\ ${ }^{1}$ Discipline of Microbiology, School of Life Sciences, University of KwaZulu-Natal (Westville Campus), Private Bag \\ X54001, Durban 4000, South Africa. \\ ${ }^{2}$ Institute for Water and Wastewater Technology, Durban University of Technology, Durban 4001, South Africa.
}

Received 5 March, 2014; Accepted 15 August, 2014

\begin{abstract}
The growth of Chlorella vulgaris in open pond aquatic conditions poses serious challenges due to the interplay of both physico-chemical and biotic factors. We report here the monitoring of physicochemical and biotic parameters affecting the propagation of $C$. vulgaris seed culture for inoculation of a large scale raceway pond (300 $000 \mathrm{~L}$ capacity) in South Africa. The C. vulgarisstrain used for this purpose was isolated from a wastewater maturation pond and characterized for its potential for biomass and lipid production. The isolate was grown aseptically in $4 \times 25 \mathrm{~L}$ aspirator bottles in BG-11 medium under ambient laboratory conditions and the culture was supplied with filtered air and exposed to 200 $\mu \mathrm{mol}$ photons per $\mathrm{m}^{2}$ per second using Gro-Lux agricultural fluorescent lights. The culture was transferred to a $500 \mathrm{~L}$ capacity portable pool under open conditions. This pond was used to further inoculate 3 more portable ponds. Physico-chemical and biotic growth parameters were monitored on a daily basis in the three ponds. The over reliance on fossil fuels will have a major impact on power supply in the near future if renewable sources of energy are not developed at a fast pace. The developed inoculum was subsequently used to inoculate an open raceway pond for large scale biomass production for biodiesel production.
\end{abstract}

Key words: Biodiesel, biomass, inoculum, lipid, raceway pond, seed culture.

\section{INTRODUCTION}

The depletion of fossil based fuels is becoming a reality as the global demand for energy fuels outpaces supply. Global energy demand is drastically increasing due to the growing world population and the improvement of the quality of human life (Razzak et al., 2013). Hence it is desirable to search for alternative, sustainable and renewable fuels such as biodiesel generated from microalgal lipids (Singh et al., 2014; Hamawand et al., 2014; Oncel, 2013; Pittmanet al., 2011). The success of this technology depends on selecting a suitable microalgal strain as well as adopting a cost effective cultivation strategy (Singh et al., 2014; Chinnasamyet al.,

*Corresponding author. E-mail: mutanda@ukzn.ac.za. Tel: +27 313608226.

Author(s) agree that this article remain permanently open access under the terms of the Creative Commons Attribution License 4.0 International License 
2010).

Successful large scale microalgal cultivation systems rely heavily on the quality, vigour and physiological properties of the seed culture, cultivation system as well as techno-economic considerations (Jonker and Faaij, 2013). In addition, the optimum combination of technical innovations in systems and processes, coupled with economic feasibility in the practical implementation and integrated scale-up for commercial production and marketing is also essential for successful development of algae based biofuels (Gendy and El-Temtamy, 2013). It is imperative to develop a seed culture propagation strategy that will result in the development of robust and high quality inoculum for seeding a large scale open raceway pond. Raceway ponds are preferred for microalgae cultivation due to a number of advantages as compared to photobioreactors (Razzak et al., 2013; Mutanda et al., 2011a; Harun et al., 2010; Chisti, 2007; Grobbelaar, 2009; Pulz and Gross, 2004).

Preliminary microalgal cultivation studies demonstrate that there are 4 fundamental steps for up scaling seed culture to be adequate to inoculate a large commercial raceway pond (Grobbelaar, 2009). The four important steps to full realisation of a high quality seed culture are: (1) bioprospecting for hyper lipid producing microalgal strain; (2) strain selection, isolation and purification using conventional and advanced methods; (3) up scaling of the seed culture under laboratory conditions in aspirator bottles and (4) seed culture propagation in a pond under open conditions (Grobbelaar, 2009; Mutanda et al., 2011a). The outdoor ponds are operated as a series of batch reactors with inoculation volumes ranging between 20 and $25 \%$ of the volumes of the next size cultures. Ambient $\mathrm{CO}_{2}$ is adequate as a carbon source for microalgal growth but however, pure $\mathrm{CO}_{2}$ gas is supplied on demand following an increase in $\mathrm{pH}$ above $\mathrm{pH} 9.5$ (Bechet et al., 2013; Grobbelaar, 2009).

The production process is a stepwise increase in volume, always starting from pure laboratory grown cultures (Grobbelaar, 2009). This is done to minimise contaminating microalgae from taking over the target culture and to ensure that only the target strain is propagated to be the dominant population for inoculation of the large scale raceway pond. Finally, the entire contents of the small seed culture ponds are transferred to the next size production ponds as inoculum and eventually to the large scale raceway pond. However, it is crucial to transfer seed culture that is at the exponential growth phase to the same media previously used for seed culture proliferation so as to minimise culture shock and to prevent a long lag phase when the seed culture is transferred to the large scale raceway pond.

The commercial cultivation of microalgae and cyanobacteria on an industrial scale began with the culture of Chlorella in Japan in the 1960s followed by the cultivation of Spirulina in Mexico, the USA and China in the 1970s (Radmann et al., 2007). Chlorella, Spirulina and Dunaliella are commonly cultivated since they can be easily grown in highly selective media and can be cultivated in open raceway ponds and remain relatively free from contamination (Radmann et al., 2007). The main beneficial factor of the open raceway pond technology is its possible low cost microalgae cultivation system with a wide array of process designs ranging from single, multichannel and cascading systems.

Other biotic factors that feed on microalgae such as invertebrates, bacteria and viruses play havoc with microalgal cultivation under open conditions. Protozoa can devour a pond of microalgae in a matter of minutes therefore it is crucial to closely monitor these contaminants. Due to unpredictable population dynamics of the raceway pond due to seasonal variability, it is crucial to monitor any succession tendencies in the ponds by nontarget microalgae. The important factors affecting microalgal growth are light intensity, temperature, nutrients, $\mathrm{pH}$ and salinity. These factors must be optimal for maximal microalgal growth and productivity. Therefore the aim of this study was to investigate the effect of physico-chemical and biotic factors on seed culture propagation in open ponds.

\section{MATERIALS AND METHODS}

\section{Materials and reagents}

Portable pools $(500 \mathrm{~L})$, fish pumps, tubings, lights and all accessories used for aerating the pools were bought from local suppliers. Aspirator bottles (Schott Duran, $25 \mathrm{~L}$ ), oven and rotavapor were purchased from Lasec, South Africa. The Spectroquant \& Pharo 300UV / VIS $190 \quad-1100 \quad \mathrm{~nm}$ spectrophotometer was purchased from Merck, South Africa. The Hach pocket colorimeter (for the determination of free and total chlorine) and powder pillows were obtained from Universal Water Solutions, South Africa. The light intensity meter and the YSI probe were purchased from Campbell Scientific Africa and Monitoring and Control Laboratories Pty Ltd respectively. All the reagents used for media preparation were of reagent grade unless otherwise stated.

\section{Microalgal strain isolation and purification}

An extensive bioprospecting exercise for hyper-lipid producing microalgae was carried out in aquatic habitats in Kwa-Zulu Natal Province, South Africa. Subsequently, a robust high lipid producing C. vulgaris was isolated from a wastewater maturation pond at Kingsburgh wastewater treatment plant in Durban, South Africa. The microalgal strain was purified to monoculture using standard conventional protocols and identified using molecular tools to determine phylogenetic affiliations as previously reported in our laboratory (Bhola et al., 2011). Sequence results from BLAST searches into the GenBank databases confirmed that the obtained sequences were homologous to ribosomal genes of $C$. vulgaris with $99 \%$ similarity and the sequences obtained were deposited to GenBank with the accession number HM046832 (Bhola et al., 2011). The purified isolate was kept at $4^{\circ} \mathrm{C}$ in suspension and routinely subcultured until needed for further research.

\section{Growth conditions and media composition}

The microalgal cultures were grown and maintained in BG-11 


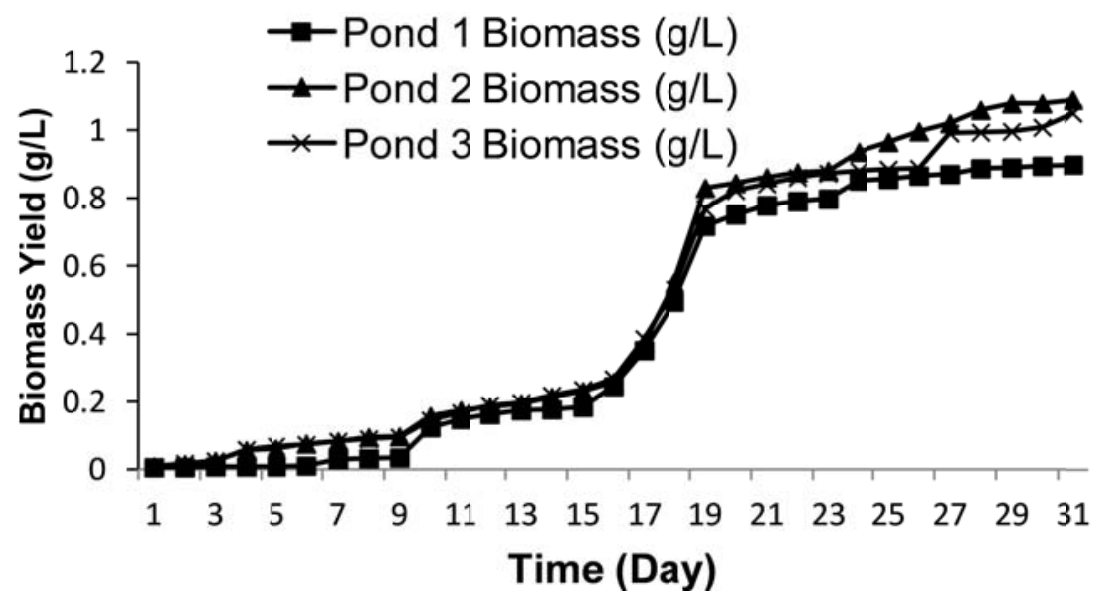

Figure 1. Graph showing biomass propagation with time in the 3 ponds.

mediumas previously described (Stanier et al., 1971; Mutanda et al., $2011 \mathrm{~b})$. A drop of tetracycline $(0.5 \mu \mathrm{l} / \mathrm{L})$ was added to the growth medium to prevent any bacterial contamination in the microalgalcultures. The $\mathrm{pH}$ was adjusted to 7.4 and trace metals were added separately after autoclaving. The BG-11 medium was used for the entire seed culture preparation. The $4 \times 25 \mathrm{~L}$ aspirator bottles were inoculated with pure seed culture $\left(10 \% \mathrm{v} / \mathrm{v}, 1.2 \times 10^{7} \mathrm{cells} / \mathrm{ml}\right)$ and incubated under ambient laboratory conditions exposed to Sylvania Grow-lux $18 \mathrm{~W}$ lights. The seed culture growth was monitored daily and routinely checked microscopically for any contamination. Evidence of microbial contamination was determined by conventional light microscopy and in addition, bacterial contamination was investigated by spreading a diluted microalgal suspension onto solidified nutrient medium containing $1 \%$ glucose, $1 \%$ peptone and $1 \%$ yeast extract. Light microscopy was used for microalgal cell counts as described in the following section.

\section{Inoculation of the open ponds}

BG-11media composition was prepared as previously reported with the exception that it was not sterilized since it was used under open conditions. A total of $500 \mathrm{~L}$ of media was prepared for each portable pond with a depth of $30 \mathrm{~cm}$ to allow maximum sunlight penetration. The three portable pools were of equal size and had a maximum capacity of $1000 \mathrm{~L}$. Each portable pool was inoculated with $10 \% \mathrm{v} / \mathrm{v}$ $\left(1.2 \times 10^{7}\right.$ cells $\left./ \mathrm{ml}\right)$ of inoculum and aeration was achieved by means of fish pumps and bubbling filtered air $(1 \mathrm{ml} / \mathrm{min})$ dispersed through 10 aquarium air stones placed equidistant from each other below the microalgal suspension. Mixing of the culture was done manually by means of swirling the suspension using a hand held pump three times a day. The air bubbling through air stones also improved mixing. Evaporation rates were monitored daily by observing the deviation from the $500 \mathrm{~L}$ mark on each portable pool and then compensated by topping up with tap water to the $500 \mathrm{~L}$ mark.

\section{Monitoring of growth parameters}

Physico-chemical parameters were measured using a calibrated YSI probe. The variables were monitored daily at $1100 \mathrm{~h}$. The following parameters were measured: $\mathrm{pH}$, temperature, salinity, evaporation rates, conductivity, dissolved $\mathrm{O}_{2}$, total dissolved solids and oxidative reduction potential (ORP). A light intensity meter was used to measure light intensity. Samples $(500 \mathrm{ml})$ were collectedfrom the ponds for laboratory analysis of microbial contaminationand determination of biomass yield.

\section{Free and total chlorine determination}

Free and total chlorine was determined using the Pocket Colorimeter (Hach) and the $N, N$-diethyl-p-phenylenediamine (DPD) free chlorine reagent as recommended by the manufacturer.

\section{Determination of biomass}

The microalgal cells were harvested daily from the portable pools by the centrifugation method. A seed culture sample $(500 \mathrm{ml})$ was centrifuged at $4000 \operatorname{RPM}\left(20\right.$ mins, $\left.4^{\circ} \mathrm{C}\right)$ and the microalgal biomass was placed in a preweighed watch glass. The biomass was dried in an oven at $60^{\circ} \mathrm{C}$ for $12 \mathrm{~h}$. The watch glass with the biomass was weighed and the net mass of the microalgal cells was determined by subtracting the final weight from the weight of the watch glass. The weight of the biomass was expressed in $\mathrm{g} / \mathrm{L}$. The cell density was measured indirectly using spectrophotometry and directly by light microscopy by performing manual cell counts using a counting chamber (haemocytometer) with Neubauer rulings as instructed by the manufacturer.

\section{RESULTS}

\section{Biomass production}

The biomass was monitored in the three ponds for 30 days and the data generated show typical growth curves (Figure 1). There was a prolonged lag phase in the three ponds and this is attributed to the open nature of the growth conditions and it took a long time for the pure monoculture to adjust to the open conditions as compared to the controlled laboratory conditions. The exponential growth phase started on the $9^{\text {th }}$ day of growth up to the $19^{\text {th }}$ where the stationary growth phase sets in. These findings clearly suggest that the inoculumn in the 


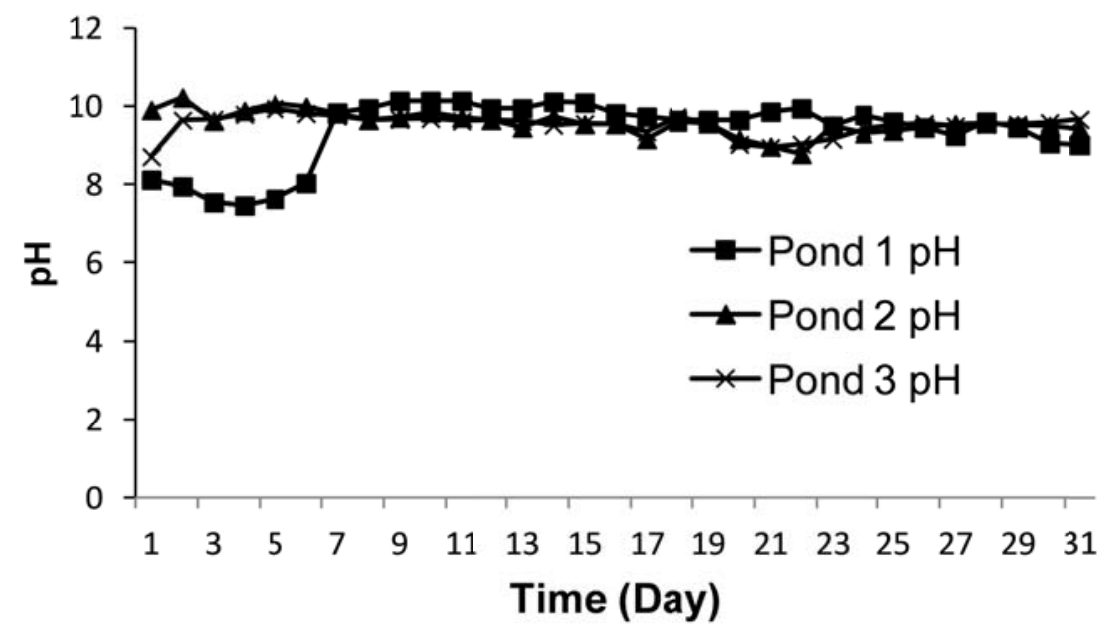

Figure 2. Graph showing pH monitoring in the three ponds.

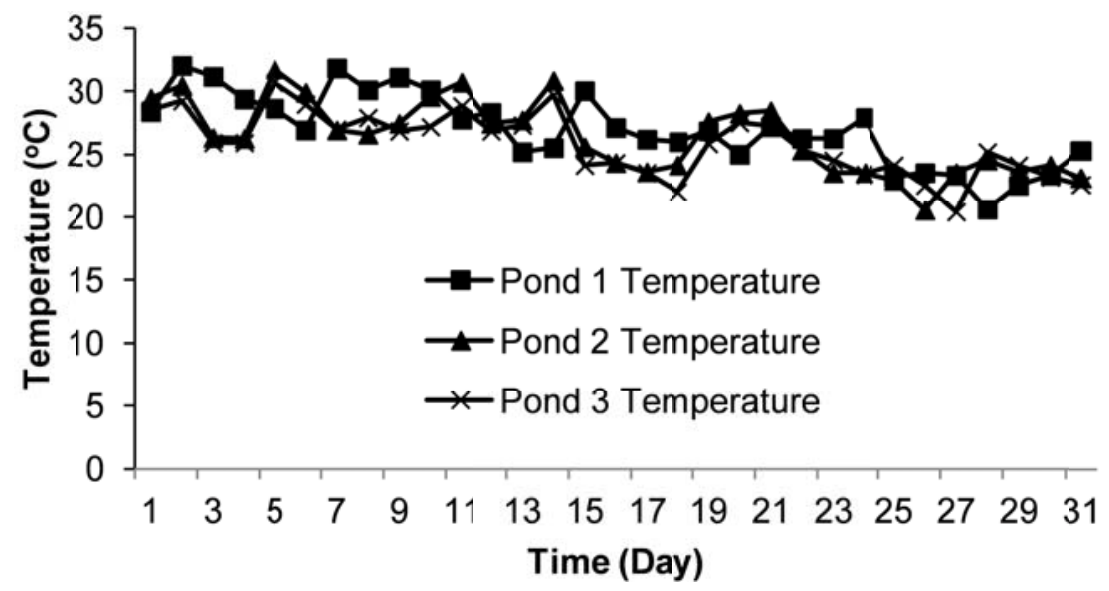

Figure 3. Graph showing temperature fluctuations in the 3 ponds.

ponds can be harvested at this prime time before the cells lose their vigour.

\section{Effect of pH on Chlorellavulgaris growth}

The $\mathrm{pH}$ values in the 3 ponds for the entire growth period were in the desirable range (Figure 2) therefore it was not necessary to supplement the ponds with additional $\mathrm{CO}_{2}$. The $\mathrm{pH}$ ranged from 7.55 to $10.14,8.78$ to 10.08 and 8.72 to 9.95 in ponds 1,2 and 3 respectively. Carbon dioxide has a strong influence on $\mathrm{pH}$ fluctuations in the growth ponds and the data generated demonstrate that the utilisation of $\mathrm{CO}_{2}$ for photosynthesis results in the formation of carbonates in the medium that pushes up the $\mathrm{pH}$ into the alkaline range.

\section{Effect of temperature on Chlorellavulgarisgrowth}

It was found that temperature ranged from 22.56 to
$32.04,20.56$ to 31.76 and 20.45 to $30.75^{\circ} \mathrm{C}$ in pond 1,2 and 3 , respectively (Figure 3 ). To validate these findings, the seasonal temperature variation at this site is suitable for microalgal cultivation throughout the year from the weather data reported by the South African Weather Services. Temperature fluctuations in the three ponds followed a similar trend since the ponds were in proximity to each other and also located at the same experimental site.

\section{Effect of Light intensity on C. vulgarisgrowth}

In the growth period under this study, the photoperiod was $8 \mathrm{~h}$ light and $12 \mathrm{~h}$ darkness. The light intensities ranged from 18.92 to $306.7,20.21$ to 462.9 and 10.31 to $315.9 \mu \mathrm{molm}^{-2} \mathrm{~s}^{-1}$ in pond 1, 2 and 3, respectively (Figure 4). At the initial growth stages, the light intensity was fairly high in all the experimental ponds and there was a gradual decline with time. 


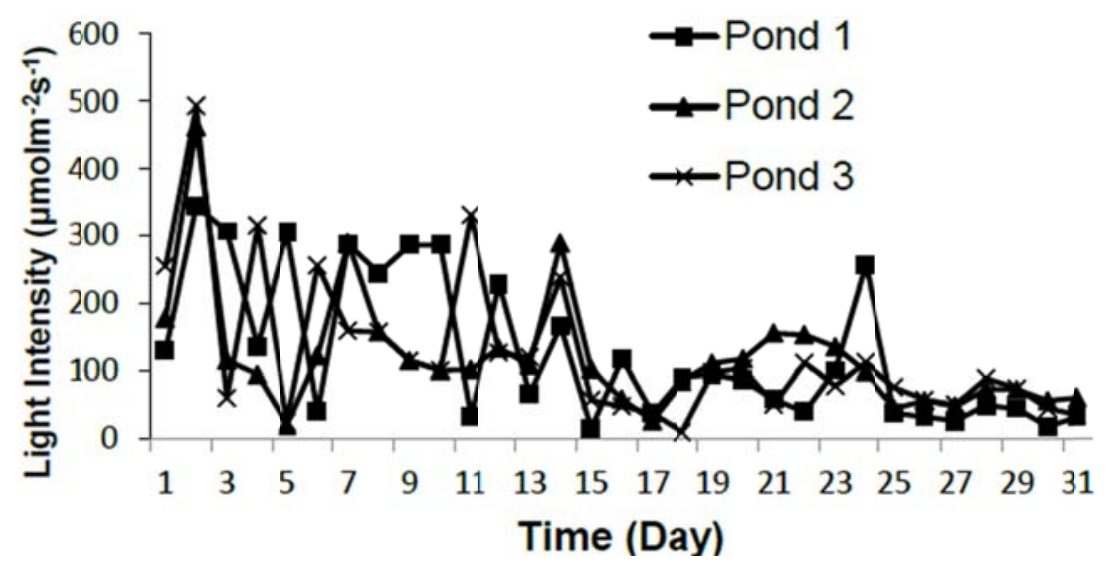

Figure 4. Graph showing light intensity in the 3 ponds.

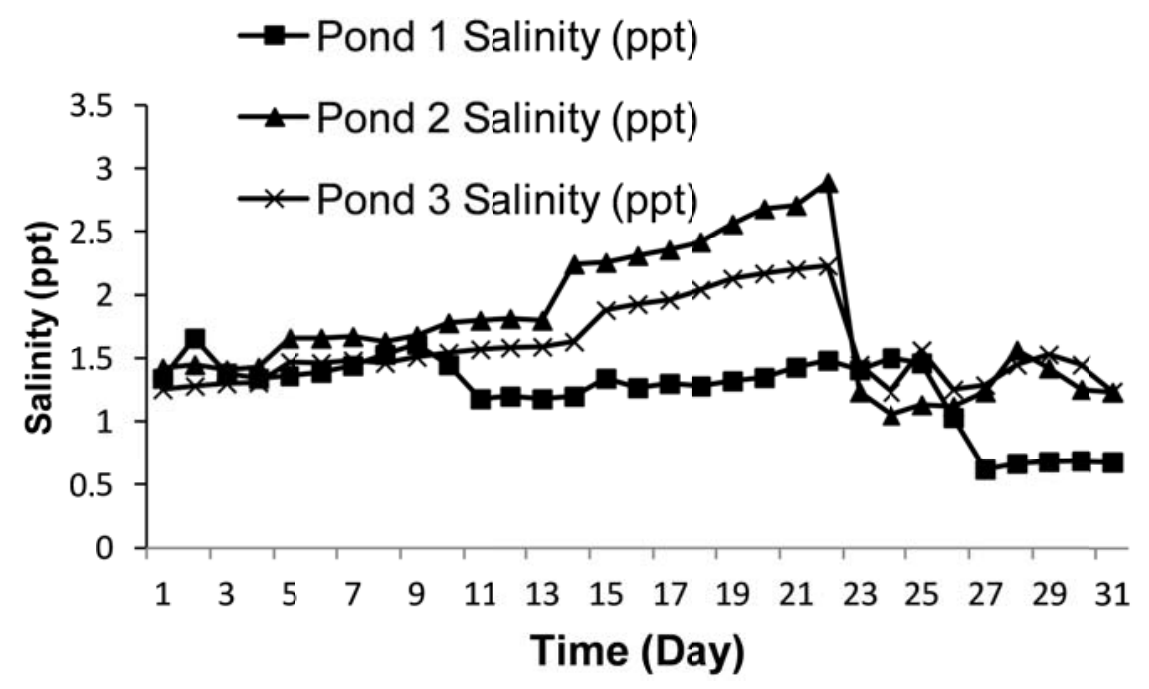

Figure 5.Graph showing salinity in the 3 ponds.

\section{Effect of salinity on C. vulgaris growth}

There was a slight increase in salinity in pond 1 from the initial 1.34 to $1.66 \mathrm{ppt}$ on day 1 of incubation and this is possibly due to salt residues on the seed culture (Figure 5 ). In both pond 2 and 3 , there was a gradual increase in salinity up to 2.89 and $2.23 \mathrm{ppt}$, respectively on day 22 and this is mainly attributed to slightly higher evaporation rates in the ponds (Figure 5). On this day, additional water $(120 \mathrm{~L})$ was added to the ponds with a corresponding decline in salinity levels. On the final day of incubation that is, day 30 , the salinity levels were 0.68 ppt, $1.23 \mathrm{ppt}$ and $1.24 \mathrm{ppt}$ in pond 1, 2 and 3 , respectively.

\section{Effect of dissolved oxygen on Chlorella vulgaris growth}

Data generated in our experiments show intermittent fluc- tuations in the concentration of dissolved oxygen with time in the three ponds. Initial $\mathrm{DO}_{2}$ concentrations were 8.05, 19.1 and $13.45 \mathrm{mg} / \mathrm{L}$ for pond 1,2 and 3 , respectively (Figure 6). The final $\mathrm{DO}_{2}$ concentrations on day 30 were $17.42,15.78$ and $17.13 \mathrm{mg} / \mathrm{L}$ for pond 1,2 and 3 , respectively (Figure 6).

\section{Effect of total dissolved solids (TDS) on Chlorella vulgaris growth}

There was a variation in TDS levels with time in the 3 ponds and a dramatic decrease in TDS $(0.815 \mathrm{~g} / \mathrm{L})$ was observed in pond 2 on day 17 (Figure 7 ). In pond one, TDS decreased from the initial 1.394 to $0.889 \mathrm{~g} / \mathrm{L}$ after 30 days of incubation. In pond 3 there was a steady increase in TDS from 1.592 to $3.116 \mathrm{~g} / \mathrm{L}$ after 28 days of incubation and thereafter the TDS concentration dropped to 2.184 after 30 days of incubation (Figure 7 ). 


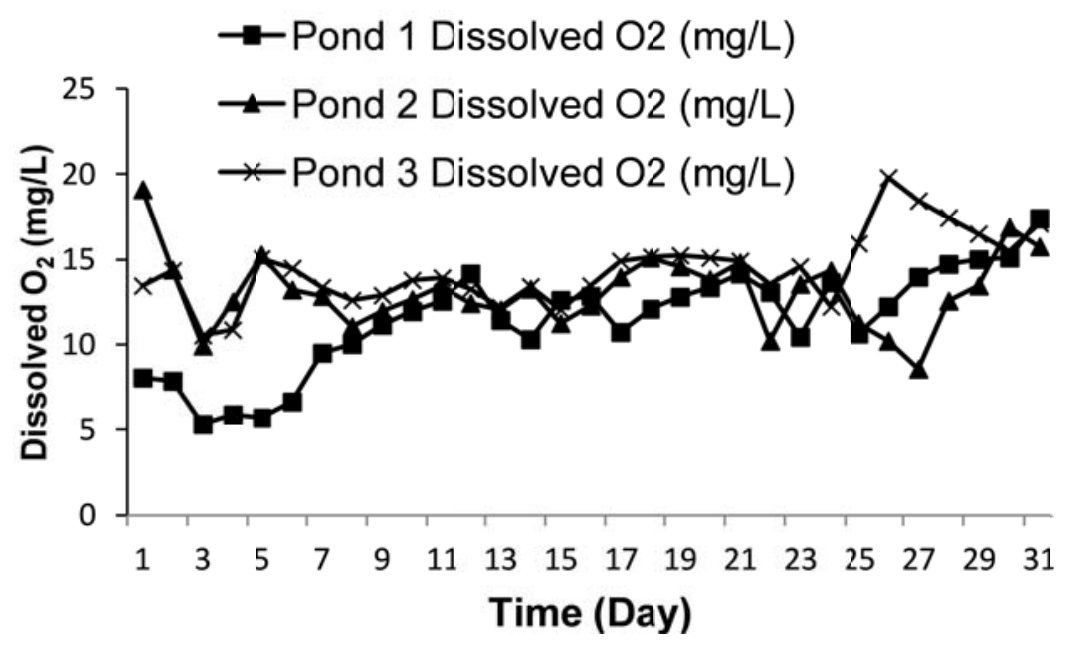

Figure 6. Graph showing dissolved oxygen in the 3 ponds.

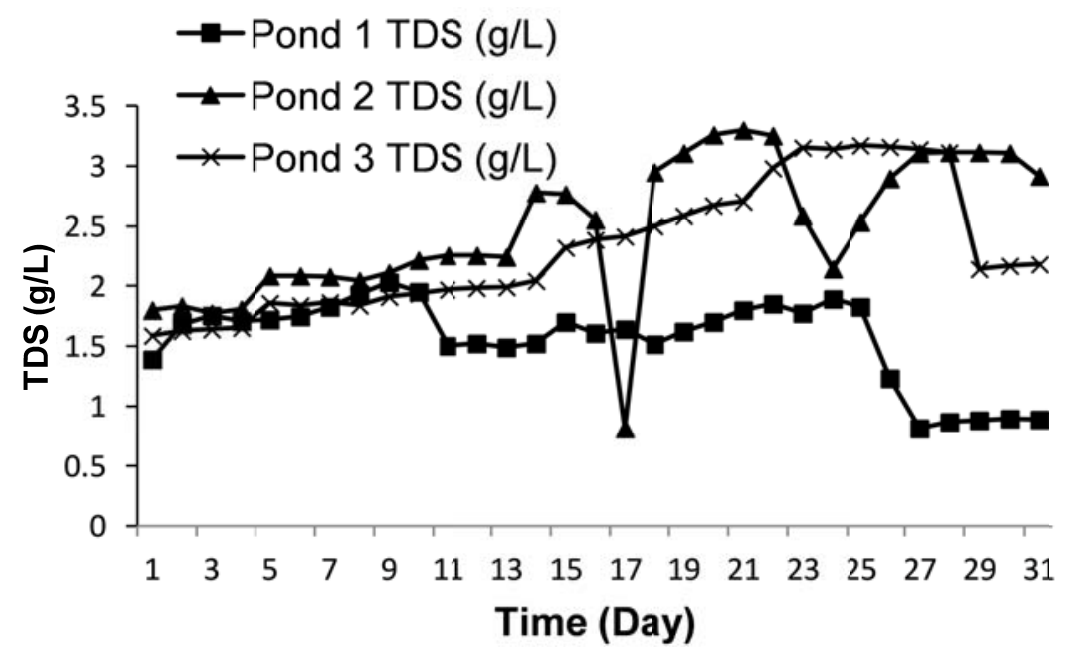

Figure 7. Graph showing total dissolved solids (TDS) in the 3 ponds.

\section{Effect of conductivity on Chlorella vulgarisgrowth}

There was a dramatic decrease in conductivity (1.214 $\mathrm{ms} / \mathrm{cm}$ ) in pond 2 on day 17 in response to a decrease in TDS (Figures 7 and 8). There was a steady decline in conductivity in pond 1 from the initial 2.774 to 1.374 $\mathrm{ms} / \mathrm{cm}$ after 30 days of incubation (Figure 8). There was a slight increase in conductivity in pond 2 from the initial 3 to $3.125 \mathrm{~ms} / \mathrm{cm}$ after 30 days of incubation. There was a steady increase in conductivity in pond 3 from the initial 2.615 to $3.415 \mathrm{~ms} / \mathrm{cm}$ after 30 days of incubation.

\section{Effect of oxidation reduction potential (ORP) on Chlorella vulgaris growth}

The results obtained in the three ponds indicate a fluctua- tion in the ORP with time (Figure 9). In pond 1, the initial and final ORP was -32 and $-77.6 \mathrm{mv}$, respectively. The same trend was observed in pond 2 where the initial and final ORP was -39.7 and $-94.5 \mathrm{mv}$, respectively. The initial and final ORP in pond 3 was -2.6 and $-74.6 \mathrm{mv}$, respectively.

\section{Effect of biotic factors on C.vulgarisgrowth}

On the last day of cultivation, microscopic analysis revealed the presence of Scenedesmus sp. in all the 3 ponds under investigation (Figure 10). In any microalgal seed preparation, it is desirable to closely monitor nontarget microbial agents in the ponds to avert collapse of the system due to contamination by the undesirable microalgal strains. 


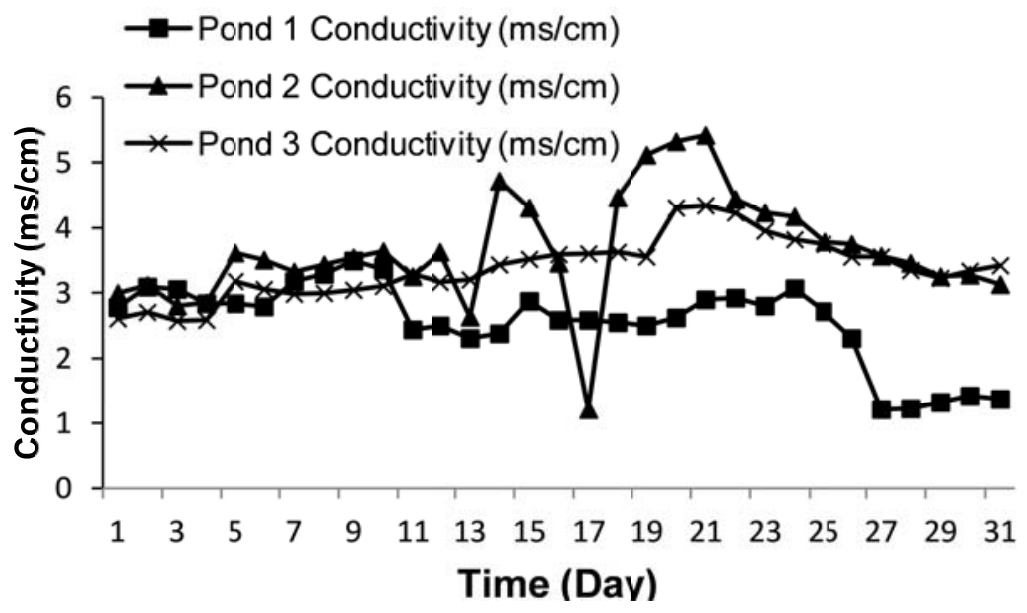

Figure 8.Graph showing conductivity in the ponds.

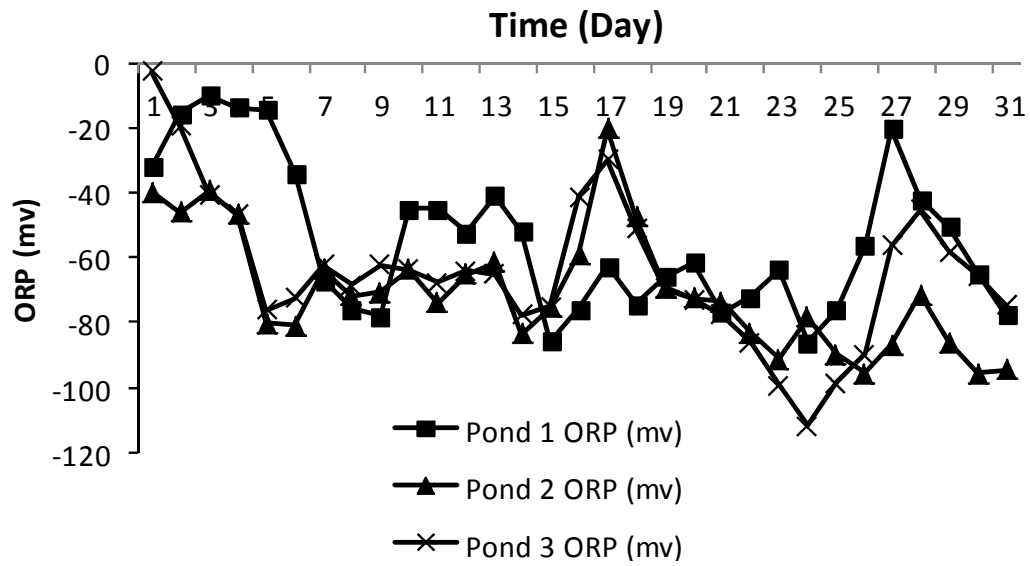

Figure 9. Graph showing oxidation reduction potential in the 3 ponds.

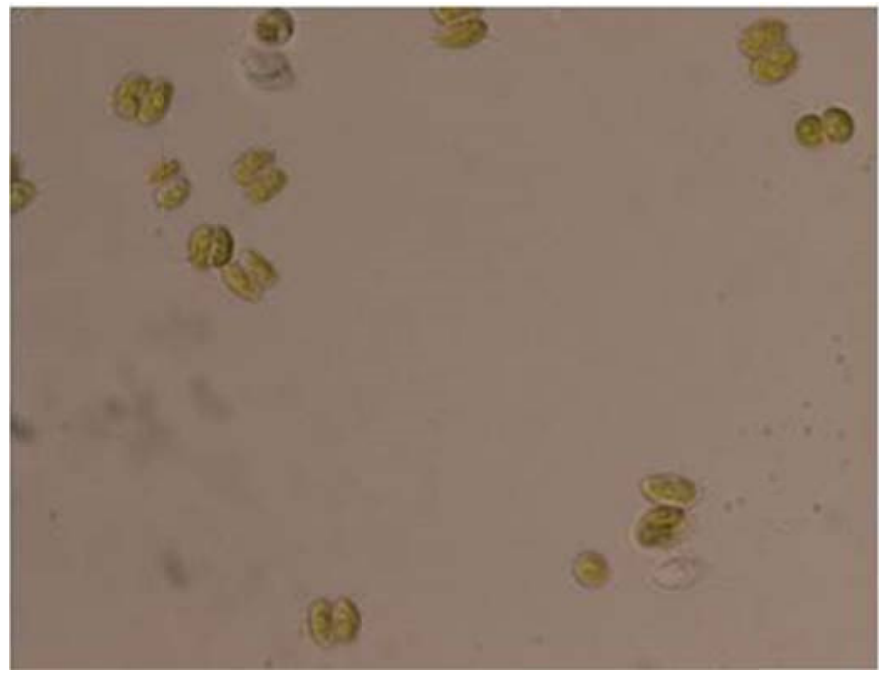

Figure 10. Light microscope slide of a wet mount of the culture in pond 1 showing the presence of Senedesmussp.in the pond (x1000). 


\section{Effect of free chlorine on C. vulgaris}

The free chlorine in the 3 ponds was determined and was found to be $0.05 \mathrm{mg} / \mathrm{L}$ on the first day of microalgal growth in the 3 ponds. However on the last day of growth, there was a slight decrease in free chlorine to $0.03 \mathrm{mg} / \mathrm{L}$ in the 3 ponds.

\section{DISCUSSION}

Similar work done by Grobbelaar(2009) also support the assumption that continued growth of microalgal cells in batch culture could negatively impact on their viability and resuscitation and rejuvenation of these cells can lead to failure when transferred to large scale raceway pond. It was observed that settling of the cells was a major stumbling block and mechanical mixing of the suspension was only achieved by physically mixing 3 times a day using a hand held pump. The maximum dry weights achieved were $0.898,1.09$ and $1.05 \mathrm{~g} / \mathrm{L}$ for pond 1,2 and 3 , respectively (Figure 1). Free chlorine is reported to be a micronutrient for microalgal growth therefore initial free chlorine in all the 3 ponds was determined and was found to be $0.05 \mathrm{mg} / \mathrm{L}$.

$\mathrm{pH}$ has a major effect on microalgal growth since it controls all metabolic and physiological functions of the cell as well as influencing biomass regulation (Mayo, 1997). The $\mathrm{pH}$ concentration range for the existence of biological life is quite narrow (typically 6-9) and an indication of extreme $\mathrm{pH}$ is known to damage biological processes in biological treatment units (Akpor and Muchie, 2011). Therefore it is imperative to closely monitor $\mathrm{pH}$ in the ponds. The $\mathrm{pH}$ levels above 9 are desirable because some contaminants such as protozoans and rotifers are inhibited under these conditions and are therefore completely eliminated from the ponds but however, invertebrates can easily survive and thrive above $\mathrm{pH}$ 9. The presence of these contaminating microorganisms can lead to disastrous consequences since they are known grazers and can therefore devour the target microalgal cells in a short space of time. There was a gradual decrease in $\mathrm{pH}$ levels in pond 1 for the first three days of growth (Figure 2) and this is attributed to accumulation of dissolved $\mathrm{CO}_{2}$ as the microalgal cells adjust to the new conditions in the open pond growth system. It is interesting to hypothesise that $\mathrm{pH}$ is strongly regulated by both $\mathrm{CO}_{2}$ concentration and photosynthetic rates in the pond. Using higher concentration of $\mathrm{CO}_{2}$ may result in decreasing the $\mathrm{pH}$ since unutilized $\mathrm{CO}_{2}$ will be converted to $\mathrm{H}_{2} \mathrm{CO}_{3}$ and on the other hand, if there is not enough $\mathrm{CO}_{2}$ gas supply, microalgae will utilize carbonate to maintain its growth (Widjaja et al., 2009). In a similar study, the addition of either or both, $\mathrm{CO}_{2}$ and combined nitrogen (as $\mathrm{KNO}_{3}$ or $\mathrm{NH}_{4} \mathrm{Cl}$ ), did not result in any increase in microalgal biomass productivity (Fontes et al., 1987). Optimal values for $\mathrm{pH}$ and temperature were $8.2-8.4$ and $30-35^{\circ} \mathrm{C}$, respectively (Fontes et al., 1987). However, the data generated was only for day time conditions and it will be interesting to monitor $\mathrm{pH}$ levels at night where photosynthesis does not take place.

Temperature is one of the most crucial factors affecting biomass accumulation and lipid production by microalgal cells since it is pivotal in all enzymological reactions and physiological functions of the cells. It is well documented that sub-tropical freshwater microalgae require temperatures in the range of 25 to $30^{\circ} \mathrm{C}$ for optimal growth (Grobbelaar, 2007).In this study, the temperature fluctuated in the 25 to $30^{\circ} \mathrm{C}$ range in agreement with data from other researchers (Mayo, 1997). Ambient temperature in this range is known to influence the biomass composition, nutrient requirements, nature of metabolism, and the metabolic reaction rates because microalgae do not have the ability to regulate their internal temperature (Carvalho et al., 2009; Mayo, 1997).

Microalgae require illumination conditions to economically achieve maximum photosynthetic rates and considering the operating conditions, light intensity (or illuminance) is one of the several parameters influencing the growth of photosynthetic organisms such as micro-algae (Zhao et al., 2013; Mata et al., 2012). Light intensity, quality and duration of exposure are the main driving forces for higher photosynthetic rates and subsequent high biomass and lipid productivities. It was reported that light intensity of around $300 \mu \mathrm{mol} / \mathrm{m}^{2} / \mathrm{s}$ is ideal for optimal microalgal growth although too much light intensities can cause photo-oxidation that is harmful to $C$. vulgaris though intermittent light fluctuations enhance microalgal productivity (Grobbelaar, 1989). In addition, previous studies have reported that varying illumination intensities in outdoor conditions are likely to inhibit microalgae growth because of the shortage in light energy, for example, very low light intensities during rainy days or the photoinhibition caused by excessive irradiance, or very high light intensities at noon times during summer (Ugwu et al., 2007). The gradual decrease in light intensity is explained by the biomass accumulation in the suspension which retarded light penetration into the media. Furthermore, the presence of clouds and rainy conditions on some days prompted the ponds to be covered by a plastic sheet hence lowering light intensity in the microalgal suspension. From our findings (Figure 4), it is generally accepted that light intensities at this site are ideal for C.vulgaris cultivation and it is feasible to grow this culture in a large scale raceway pond.

The additional expenditure of metabolic energy under stress conditions is required for maintaining ion homeostasis and electrochemical gradients, for the biosynthesis of organic compounds which play an important role in protection and osmoregulation, and for supporting the maintenance of cellular structure (Alyabyev et al., 2007). In addition, salinity controls the osmotic potential of the suspension therefore has a strong influence on the water 
relations of the microalgal cells. For small scale laboratory shake flask experiments, it is recommended to wash the cells with ammonium formate and deionised water to remove the salt residues (Chinnasamy et al., 2010). The salinity levels recorded for the three ponds are ideal for C.vulgarisgrowth. High salinity is reported to increase lipid production by microalgae but however, too high salinity levels above the threshold are detrimental to C.vulgaris and can lead to microalgal growth inhibition (Ho et al., 2010).

Environmental conditions such as temperature, salinity and atmospheric pressure greatly affect oxygen solubility in water. The dissolved oxygen is an important parameter for microalgal respiration and therefore energy production. The subsequent biomass and lipid yield is affected by the dissolved oxygen in the medium. The dissolved $\mathrm{O}_{2}$ saturation in freshwater under atmospheric pressure at $20^{\circ} \mathrm{C}$ is $9.1 \mathrm{mg} / \mathrm{L}$. The elevated dissolved oxygen concentrations on the final day of cultivation are explained by continuous and cumulative oxygen evolution due to microalgal photosynthesis, therefore exceeding the $\mathrm{DO}_{2}$ concentration standard for freshwater. Elevated levels of dissolved oxygen are not desirable in the culture because it is well-known that dissolved oxygen is lethal to microalgal cells (Suali and Sarbatly, 2013).

Total dissolved solids (TDS) is a measure of the combined content of all inorganic and organic substances contained in the aqueous suspension in molecular, ionized or micro-granular suspended form. Salinity also comprises some of the ions that constitute TDS. The most common chemical constituents of TDS are calcium, phosphates, nitrates, sodium, potassium and chloride ions. These ions are readily found in BG-11 medium used in this investigation. The findings (Figure 7) demonstrate that TDS is a function of both salinity and evaporation rates. Microalgae cultivated in raceway pond remove TDS as they use the organic and inorganic ions for their primary production (MoheimaniandBorowitzka, 2006; Park et al., 2011). However, the TDS contributed by dust and clay particles cannot be eliminated by the microalgal cells. The presence of debris in the ponds could potentially lead to bacterial contamination and all the leaves and grass components that fell in the ponds were routinely removed from the ponds to alleviate this.

Conductivity is a measure of a material's ability to conduct an electrical current and due to the presence of electrolytes in BG-11 medium, conductivity is an important parameter to measure so as to establish general utilisation of the inorganic materials in the medium by the microalgal cells. Conductivity is closely associated with TDS and salinity and this is manifested by the findings obtained in this investigation (Figure 8). The phenomenon observed is explained by the bioavailability of chemical species in the BG-11 medium whose uptake by the microalgal cells led to a decrease in conductivity in the aqueous microalgal suspension.

ORP is a tendency of a chemical species to acquire electrons and thereby become reduced. The more positive the potential, the greater the species' affinity for electrons and tendency to be reduced. The more negative values for the ORP (Figure 9) are explained by the evolution of $\mathrm{O}_{2}$ due to photosynthesis of the $C$. vulgaris cells and this indicate the vigour and robustness of the strain used with incubation time.

It has been reported that biotic factors that may impact negatively on algal growth include pathogenic bacteria and predatory zooplankton and also that the other microorganisms may outcompete the target microalgal strain for essential nutrients (Pittman et al., 2011). Microscopic analysis of the cells was routinely done to check for contamination in the ponds. It is documented that under open cultivation system, Chlorella and Scenedesmussp. usually coexist and are the predominant strains of the phytoplanktonic communities (Pittman et al., 2011).

In conclusion, this investigation clearly demonstrated that for successful seed culture preparation, there is need to closely monitor physico-chemical and biotic factors in the cultivation ponds. Under optimal conditions, these factors can lead to high growth rates of the target microalgal strains. However under the open system, it is very difficult to control the environmental factors and as a rule of thumb, population dynamics of the microalgae and any contaminants must be routinely monitored microscopically.

\section{Conflict of Interests}

The author(s) have not declared any conflict of interests.

\section{ACKNOWLEDGEMENTS}

This material is based upon work supported by the National Research Foundation (South Africa) and Claude Leon Foundation (South Africa). In addition, the authors would also like to thank Durban University of Technology and EThekwini Municipality for funding this project.

\section{REFERENCES}

Akpor OB, Muchie M (2011). Environmental and public health implications of wastewater quality. Afr. J. Biotechnol. 10(13): 23792387.

Alyabyev AJ, Loseva NL, Gordon LK, Andreyeva IN, Rachimova GG, Tribunskih VI, Ponomareva AA, Kemp RB (2007). The effect of changes in salinity on the energy yielding processes of Chlorella vulgaris and Dunaliella maritime cells. Thermochim. Acta. 458: 65-70.

Bechet Q, Shilton A, Guieysse, B (2013). Modeling the effects of light and temperature on algae growth: State of the art and critical assessment for productivity prediction during outdoor cultivation.Biotechnol. Adv. 31(8):1648-1663.

Bhola V, Ramesh D, Kumari-Santosh S, Karthikeyan S, Elumalai S, Bux $F$ (2011). Effects of parameters affecting biomass yield and thermal behavior of Chlorella vulgaris. J. Biosci. Bioeng. 111: 377-382.

Carvalho AP, Monteiro CM, Malcata FX (2009). Simultaneous effect of irradiance and temperature on biochemica composition of the micro- 
alga Pavlovalutheri.J. Appl. Phycol. 21: 543-552.

Chinnasamy S, Bhatnagar A, Hunt RW, Das KC (2010). Microalgae cultivation in a wastewater dominated by carpet mill effluents for biofuel applications.Bioresour. Technol. 101:3097-3105.

Chisti Y (2007). Biodiesel from microalgae.Biotechnol. Adv. 25:294-306.

Fontes AG, Vargas MA, Moreno J, Guerrero MG, Losada M (1987).Factors affecting the production of biomass by a nitrogenfixing blue-green alga in outdoor culture.Biomass 13:33-43.

Gendy TS, El-Temtamy SA (2013). Commercialization potential aspects of microalgae for biofuel production: An overview. Egypt. J Petrol. 22:43-51.

Grobbelaar JU (1989). Do light/dark cycles of medium frequency enhance phytoplankton productivity. J. Appl. Phycol.1: 333-340.

Grobbelaar JU (2007). Photosynthetic characteristics of Spirulina platensis grown in commercial-scale open outdoor raceway ponds: what do the organisms tell us? J. Appl. Phycol. 19: 591-598.

Grobbelaar JU (2009). From laboratory to commercial production: a case study of a Spirulina (Arthrospira) facility in Musina, South Africa. J. Appl. Phycol. 21:523-527.

Harun R, Singh M, Forde GM, Danquah MK (2010). Bioprocess engineering of microalgae to produce a variety of consumer products. Renew. Sustain. Energy Rev. 14:1037-1047.

Ho SH, Chen WM, Chang JS (2010). Scenedesmusobliquus CNW-N as a potential candidate for $\mathrm{CO}_{2}$ mitigation and biodiesel production.Bioresour. Technol. 101:8725-8730.

Jonker JGG, Faaij APC (2013). Techno-economic assessment of microalgae as feedstock for renewable bio-energy production. Appl. Energy 102: 461-475.

Mata TM, Melo AC, Simões M, Caetano NS (2012). Parametric study of a brewery effluent treatment by microalgae Scenedesmusobliquus.Bioresour. Technol. 107:151-158.

Mayo AW (1997). Effects of Temperature and pH on the kinetic growth of unialgaChlorella vulgaris cultures containing bacteria. Water Environ. Res. 69: 64-72.

Moheimani NR, Borowitzka MA (2006). The long-term culture of the coccolithophorePleurochrysiscarterae(Haptophyta) in outdoor raceway ponds. J. Appl. Phycol. 18: 703-712.

Mutanda T, Karthikeyan S, Bux F (2011b). The utilization of postchlorinated municipal domestic wastewater for biomass and lipid production by Chlorella spp. under batch conditions. Appl. Biochem. Biotechnol.164: 1126-1138.
Mutanda T, Ramesh D, Karthikeyan S, Kumari S, Anandraj A Bux F (2011a). Bioprospecting for hyper-lipid producing microalgal strains for sustainable biofuel production. Bioresour. Technol. 102: 57-70.

Oncel SS (2013).Microalgae for a macroenergy world.Renew. Sustain. Energy Rev. 26:241-264.

Park JBK, Craggs RJ, Shilton AN (2011). Wastewater treatment high rate algal ponds for biofuel production.Bioresour. Technol. 102:35-42.

Pittman JK, Dean AP, Osundeko O (2011). The potential of sustainable algal biofuel production using wastewater resources.Bioresour. Technol. 102:17-25.

Pulz O, Gross W (2004). Valuable products from biotechnology of microalgae. Appl. Microbiol. Biotechnol.65: 635-648.

Radmann EM, Reinehr CO, Costa JAV (2007). Optimization of the repeated batch cultivation of microalga Spirulinaplatensis in open raceway ponds. Aquaculture 265:118-126.

Razzak S.A., Hossain MM, Lucky RA, Bassi AS, Lasa H (2013). Integrated $\mathrm{CO}_{2}$ capture, wastewater treatment and biofuel production by microalgae culturing- A review. Renew. Sustain. Energy Rev. 27:22-653.

Singh B, Guldhe A, Rawat R, Bux F (2014). Towards a sustainable approach for development of biodiesel from plant and microalgae. Renew. Sustain. Energy Rev. 29:216-245.

Stanier RY, Kunisawa R, Mandel M, Cohen-Bazier G (1971). Purification and properties of unicellular blue-green algae (order Chroococcales). Bacteriol.Rev. 35: 171-205.

Suali E, Sarbatly R (2012). Conversion of microalgae to biofuel.Renew. Sustain. Energy Rev.16:4316-4342.

Ugwu CU, Aoyagi H, Uchiyama H (2007). Influence of irradiance, dissolved oxygen concentration, and temperature on the growth of Chlorella sorokiniana. Photosynthetica 45: 309-311.

Widjaja A, Chien CC, Ju YH (2009). Study of increasing lipid production from fresh water microalgae Chlorella vulgaris. J. Taiwan Inst. Chem. E. 40:13-20.

Zhao Y, Wang J, Zhang H, Yan C, Zhang Y (2013). Effects of various LED light wavelengths and intensities on microalgae-based simultaneous biogas upgrading and digestate nutrient reduction process. Bioresour. Technol. 136: 461-468. 